\title{
Alpha-Ketoglutarate as a Molecule with Pleiotropic Activity: Well-Known and Novel Possibilities of Therapeutic Use
}

\author{
Barbara Zdzisińska $^{1}$ Aleksandra $\dot{Z}_{u^{\prime}}$ Ak $^{1} \cdot$ Martyna Kandefer-Szerszeń $^{1}$
}

Received: 21 December 2015/ Accepted: 22 February 2016/Published online: 20 June 2016

(C) The Author(s) 2016. This article is published with open access at Springerlink.com

\begin{abstract}
Alpha-ketoglutarate (AKG), an endogenous intermediary metabolite in the Krebs cycle, is a molecule involved in multiple metabolic and cellular pathways. It functions as an energy donor, a precursor in the amino acid biosynthesis, a signalling molecule, as well as a regulator of epigenetic processes and cellular signalling via protein binding. AKG is an obligatory co-substrate for 2-oxoglutarate-dependent dioxygenases, which catalyse hydroxylation reactions on various types of substrates. It regulates the activity of prolyl-4 hydroxylase, which controls the biosynthesis of collagen, a component of bone tissue. AKG also affects the functioning of prolyl hydroxylases, which, in turn, influences the function of the hypoxia-inducible factor, an important transcription factor in cancer development and progression. Additionally, it affects the functioning of enzymes that influence epigenetic modifications of chromatin: ten-eleven translocation hydroxylases involved in DNA demethylation and the Jumonji C domain containing lysine demethylases, which are the major histone demethylases. Thus, it regulates gene expression. The metabolic and extrametabolic function of AKG in cells and the organism open many different fields for therapeutic interventions for treatment of diseases. This review presents the results of studies conducted with the use of AKG in states of protein deficiency and oxidative stress conditions. It also discusses current knowledge about AKG as an immunomodulatory agent and a bone anabolic factor. Additionally, the regulatory role of AKG and its
\end{abstract}

Barbara Zdzisińska

basiaz@ poczta.umcs.lublin.pl

1 Department of Virology and Immunology, Institute of Microbiology and Biotechnology, Maria Curie-Sklodowska University, Akademicka 19, 20-033 Lublin, Poland structural analogues in carcinogenesis as well as the results of studies of AKG as an anticancer agent are discussed.

Keywords Alpha-ketoglutarate - Antioxidative factor . Dietary supplement · Immunomodulatory agent .

Bone anabolic agent . Anticancer agent

\section{Introduction}

Metabolites, small-molecular weight molecules, are the substrates and products of enzymatic reactions that occur naturally within cells. Among these substances, there is alpha-ketoglutarate (AKG; also known as 2-oxoglutarate, 2-oxopentanedioic acid), an endogenous intermediary metabolite in the Krebs cycle (the citric acid cycle or the tricarboxylic acid cycle, TCA) (Krebs and Johnson 1980). For many years, AKG has been an object of interest for researchers from various fields of science due to its essential role in several biological processes and its broad application scope.

AKG is an important biological molecule that plays a key role in multiple metabolic and cellular pathways. As a Krebs cycle metabolite, it regulates anabolic and catabolic TCA products and substrates, thereby regulating amino acid synthesis, ATP production, and reducing equivalent $\left(\mathrm{NAD}^{+} /\right.$ $\mathrm{NADH})$ generation, which in turn can influence reactive oxygen species (ROS) levels (Krebs and Johnson 1980). AKG is also an obligatory co-substrate for 2-oxoglutarate-dependent dioxygenases (2-OGDDs) (McDonough et al. 2010; Schofield and Zhang 1999), a large group of phylogenetically conserved enzymes, which catalyse hydroxylation reactions on various types of substrates including proteins, nucleic acids, lipids, and metabolic intermediates. These enzymes require the presence of $\mathrm{Fe}(\mathrm{II})$ as a cofactor as well as $\mathrm{O}_{2}$ and 
AKG as co-substrates. In the hydroxylation reaction of the substrate, one oxygen atom from $\mathrm{O}_{2}$ is attached to a hydroxyl group in the substrate while the other one is taken up by AKG, which leads to decarboxylation of $\mathrm{AKG}$ and subsequent formation of $\mathrm{CO}_{2}$ and succinate. Ascorbic acid (vitamin $\mathrm{C}$ ) also takes part in these reactions by inducing reduction of oxidised $\mathrm{Fe}(\mathrm{IV})$ to $\mathrm{Fe}$ (II) and restoring the activity of 2-OGDD enzymes. In humans, there are more than 60 different 2-OGDDs, and some of these enzymes play a key role in physiologically important processes such as the hypoxic response, fatty acid metabolism, nucleic acid repair and modification, and epigenetic regulation (Hausinger 2004; Rose et al. 2011). As a substrate of hydroxylases, belonging to OGDDs, AKG exerts an impact on prolyl/aspartyl/lysyl hydroxylations, which in turn regulates the stability of the hypoxia-inducible factor (HIF)-1 and collagen synthesis. Prolyl hydroxylases PHD1-3 influence the function of HIF-1 (Bruick and McKnight 2001; Epstein et al. 2001; Hirsilä et al. 2003), an important transcription factor in cancer development and progression, while prolyl-3 and prolyl-4 hydroxylases $(\mathrm{P} 3 \mathrm{H}, \mathrm{P} 4 \mathrm{H})$ control the biosynthesis of collagen (Kivirikko and Pihlajaniemi 1998), a very important component of bone tissue. AKG is also a required substrate of the Jumonji C domain containing lysine demethylases (KDM27), which are the major histone demethylases (Tsukada et al. 2006) and ten-eleven translocation hydroxylases (TET1-3) involved in DNA demethylation, which catalyse the oxidative decarboxylation of AKG, generating 5-hydroxy-methylcytosine (5-hmC) and leading to epigenetic effects (Ito et al. 2010; Tahiliani et al. 2009). Moreover, AKG binds and regulates $G$ protein function, because it is a ligand for the $G$ protein-coupled receptor (GPR99/GPR80 or OXGR1), which acts exclusively through a Gq/11-mediated pathway (He et al. 2004). Signalling through this pathway mobilises intracellular $\mathrm{Ca}^{2+}$ (via activation of phospholipase $\mathrm{C}$ ), which acts as a diffusible second messenger regulating a wide range of vital cell functions, including cellular metabolism and growth as well as cell division and differentiation (Mizuno and Itoh 2009). In this way, AKG can also function as a signalling molecule. The GPR99 receptor has so far been found in kidney, placenta, testis, smooth muscles, trachea, and mast cells (He et al. 2004; Wittenberger et al. 2002), however, its physiological role has been recently described only in kidney, where it regulated the acid-base balance in the kidney tubules in an AKG-dependent manner (Tokonami et al. 2013).

Recently, it has been shown that supplementation of AKG to adult Caenorhabditis elegans delays ageing of this nematode. These studies revealed a novel binding protein of AKG, namely the ATP synthase beta subunit (Chin et al. 2014). This finding suggests that regulatory networks acted upon by $\mathrm{AKG}$ are more complex than it was previously supposed.
The metabolic and extrametabolic function of AKG in cells and the organism open many different fields for therapeutic interventions for treatment of diseases. Metabolism is closely linked with ageing. The main symptoms of ageing, among others, are disturbances in protein metabolism and altered bone metabolism. Abnormal protein metabolism is also observed after trauma (Engel et al. 2003), surgery (Vinnars et al. 1975), burns (Biolo et al. 2000), or infections (Askanazi et al. 1980). Given its metabolic properties, AKG may be useful in reducing this type of disorders. Moreover, altered metabolism is a feature of cancer cells (Jeong and Haigis 2015). Evidence from recent years has shown that the mitochondrial genes of Krebs cycle enzymes may function as oncogenes or tumour suppressors by influencing different cellular processes. Genes encoding succinate dehydrogenase (SDH) and fumarate hydratase (FH) act as tumour suppressors (Astuti et al. 2001; Baysal et al. 2000; Burnichon et al. 2010; Castro-Vega et al. 2014; Tomlinson et al. 2002). Mutations thereof lead to accumulation of succinate and fumarate, structural analogues of AKG and oncometabolites, which have a tumourigenic role by inhibiting the activity of PHD enzymes and inducing pseudo-hypoxia (Pollard et al. 2005). In contrast, isocitrate dehydrogenase (IDH1/2) genes (products of which catalyse the oxidative decarboxylation of isocitrate to $\mathrm{AKG}$ ) act as oncogenes (Amary et al. 2011; Borger et al. 2012; Mardis et al. 2009; Parsons et al. 2008). Mutations in these genes lead to production of changed enzymes, which reduce $A K G$ to another oncometabolite- $R(-)$-2-hydroxyglutarate $(2 \mathrm{HG})$ (Dang et al. 2009). All the oncometabolites mentioned above modulate (inhibit) the activity of PHD, TET, and KDM enzymes and in this way they participate in the pathogenesis of many cancers. In this case, AKG could be used for reactivation of 2-OGDD enzymes and reversal of metabolic alterations (Fig. 1).

\section{The Formation of AKG in the Krebs Cycle and its Metabolism}

AKG is a key intermediate in the TCA cycle, the energyproducing process that occurs in cells. TCA is a cyclic pathway of eight enzymatic reactions, which oxidises compounds derived from glucose, fatty acids, and amino acids in the matrix of mitochondria, leading to formation of $\mathrm{CO}_{2}$ and reduced coenzymes (NADH and $\mathrm{FADH}_{2}$ ). These coenzymes feed electrons to the respiratory chain further used to generate ATP. In the TCA cycle, AKG is formed from isocitrate by oxidative decarboxylation catalysed by IDH. It can be further converted by AKG dehydrogenase to succinyl-CoA and NADH (Krebs and Johnson 1980). 


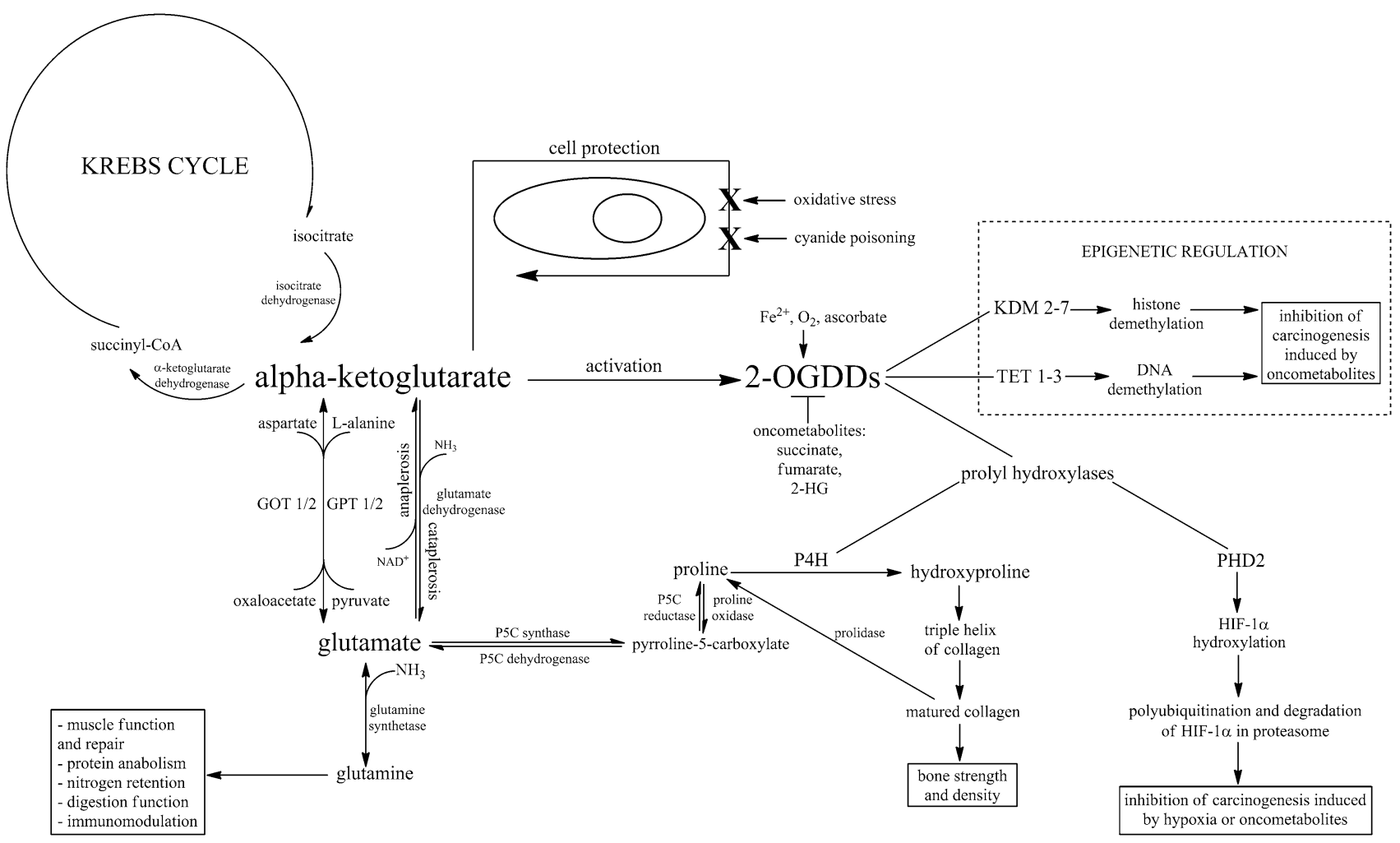

Fig. 1 Schematic representation of the pleiotropic activity of the AKG molecule. Alpha-ketoglutarate is a precursor of glutamine which contributes to muscle repair, prevents protein catabolism, improves nitrogen retention, functions as an immunomodulatory molecule, and takes part in proper function of intestines. AKG is also involved in cell protection against oxidative stress and cyanide poisoning. It can also influence bone strength and density and inhibit carcinogenesis induced by oncometabolites or hypoxia by activating enzymes from the 2-OGDD family (2-oxoglutarate-dependent dioxygenases). Their action involves epigenetic regulation such as histone

The amount of AKG produced in mitochondria depends on the state of oxidation-reduction (redox). The advantage of $\mathrm{NAD}^{+}$over NADH leads to oxidative decarboxylation of AKG and formation of succinyl-CoA, while in the case of an increased concentration of NADH and a shortage of $\mathrm{NAD}^{+}$, reductive transamination of AKG takes place with the participation of glutamate dehydrogenase, leading to formation of glutamate (Owen et al. 2002). Glutamate formed in this reaction can then, in the reaction involving glutamine synthetase, attach another ammonium ion, which results in formation of glutamine (Krebs 1935). AKG can also be produced in the reaction of glutamate and pyruvate catalysed by glutamate pyruvate transaminases (GPT1/2). Additionally, the reversible transfer of an amino group $\left(\mathrm{NH}_{3}{ }^{+}\right)$from glutamate to oxaloacetate also results in the formation of AKG (and aspartate). This reaction is catalysed by glutamate oxaloacetate transaminase, which exists in cytoplasmic and inner-membrane mitochondrial forms, and DNA demethylation carried out by KDM 2-7 (Jumonji C domain containing lysine demethylases) and TET 1-3 (10-11 translocation hydroxylases), respectively, and non-epigenetic regulation, which includes activation of prolyl hydroxylases: $\mathrm{P} 4 \mathrm{H}$ (prolyl 4-hydroxylase) involved in type I collagen biosynthesis and PHD2 (prolyl hydroxylase domain-containing protein 2 ) responsible for hydroxylation and thus inactivation of HIF- $1 \alpha$ (hypoxia-inducible factor). Other cofactors for the 2-OGDD enzymes are $\mathrm{Fe}^{2+}, \mathrm{O}_{2}$, and ascorbate while their inhibitors known as oncometabolites include succinate, fumarate, and 2-HG (R(-)-2-hydroxyglutarate)

GOT1 and GOT2, respectively (Yudkoff et al. 1994; for review see Sookoian and Pirola 2015).

The TCA cycle metabolites can penetrate to the cytoplasm, where they can be used as precursors for biosynthetic reactions. AKG can freely diffuse through channels (such as voltage-dependent anion channels) in the outer mitochondrial membrane, and it is transported across the inner mitochondrial membrane through the oxoglutarate carrier (OGC), also known as an oxoglutarate/malate antiporter. The OGC plays an important role in the malateaspartate shuttle and the oxoglutarate-citrate (isocitrate) shuttle (Chappell 1968; for review see Monné et al. 2013; Palmieri et al. 1972).

Because AKG is a key intermediate in the Krebs cycle, it is mainly found in cells (in mitochondria and cytoplasm), but it can also be detected in small quantities $(\mu \mathrm{M})$ in the bloodstream (Martin et al. 1989; Rocchiccioli et al. 1984; Wagner et al. 2010). However, in people over 40 years of 
age its level is gradually reduced (to the quantity of $\mathrm{ng} / \mathrm{ml}$ ) (Harrison and Pierzynowski 2008). Presumably, AKG present in blood may derive from the bacterial flora inhabiting the intestine, as different bacteria secrete this metabolite (Otto et al. 2011). Interestingly, physiological increases in AKG levels have been observed in the blood of humans after physical exercise (Brugnara et al. 2012), in the liver of starved pigeons (Kaminsky et al. 1982), and in starved C. elegans (Chin et al. 2014).

AKG is an important intermediate in the biosynthesis of amino acids. Cataplerotic reactions that prevent the accumulation of excess AKG in the cell are associated with production of two amino acids: glutamate and glutamine, which are very important for energy metabolism. These two amino acids play a key role in many metabolic pathways and determine proper functioning of organs such as kidney, intestine, liver, as well as pancreatic $\beta$ cells, neurons, and cells of the immune system (Newsholme et al. 2003).

In various physiological and pathological states, the body may experience an increase in protein catabolism. In these states, glutamine from the muscle and lung tissue is released and becomes available to other organs (such as the intestine or kidneys) and to immune cells. To increase its levels in the body and thus reduce the catabolic response, or even increase protein anabolism, a relevant clinical nutrition therapy (enteral and parenteral) is applied (Stehle et al. 1989). However, the use of glutamine in such a therapy has not found widespread use in medicine, due to the instability of aqueous solutions of this amino acid. Nowadays glutamine supplementation in parenteral nutrition is indicated primarily for patients in critical conditions (Al Balushi et al. 2013; Stein et al. 2009). Similarly, glutamate, from which glutamine can be synthesised de novo, is not routinely used in nutritional therapy because of its relative neurotoxicity and poor permeability across cell membranes (Hermanussen and Tresguerres 2005). In contrast, as an exogenous glutamine precursor that can be used in many deficiency states, AKG has been an object of interest for researchers and clinicians for many years. Many in vivo studies (Cynober et al. 1984, 1990; Dąbek et al. 2005; Filip and Pierzynowski 2008; Junghans et al. 2006; Loï et al. 2005) demonstrate that exogenous AKG administered as a dietary supplement in the form of various salts (ornithine, sodium, calcium) is absorbed by the organism and can be metabolised to glutamine and glutamate as well as to other amino acids (proline, arginine).

Experimental studies performed on animals have shown that ingested AKG, glutamine, and glutamate are absorbed in the upper small intestine and then metabolised in enterocytes. During the first pass metabolism in the intestinal mucosa, up to $95 \%$ of glutamate, $70 \%$ of glutamine, and only $40 \%$ of AKG is degraded to $\mathrm{CO}_{2}$ (Junghans et al.
2006). The remaining part of AKG may be used in various anabolic pathways, both in the enterocytes and in peripheral tissues, because up to $20 \%$ of dietary AKG appears in the bloodstream (Filip and Pierzynowski 2008). After absorption, this part of AKG can be used for the synthesis of amino acids such as glutamine or proline. AKG is rapidly removed from the bloodstream, and its half-life is less than 5 min (Cynober et al. 1990; Dạbek et al. 2005). The circulating AKG is passed to the liver and kidney using a sodium-potassium pump (Stoll et al. 1991; Welborn et al. 1998). Cell culture experiments have demonstrated that AKG can be easily passed to fibroblasts by simple diffusion (Aussel et al. 1996). However, the other cell culture research suggests that the ability of AKG to penetrate cells is relatively weak but can be increased by the use of its esters (Koivunen et al. 2007; MacKenzie et al. 2007). AKG is fully metabolised by the body and no excretion of the compound in the pure form with urine or faeces is observed. Studies with the sodium salt of ${ }^{14} \mathrm{C}$ labelled AKG revealed the presence of AKG carbon in several tissues (liver, brain, skin, muscle, bone tissue) already after $3 \mathrm{~h}$ of administration of the compound (Filip and Pierzynowski 2008).

\section{AKG and Protection of Cells Against Oxidative Stress}

Free radicals also known as ROS are important mediators in cell damage and cell death processes (Sena and Chandel 2012). They are involved in a variety of pathological conditions, attacking various cellular macromolecules. ROS can cause peroxidation of lipids forming cell membranes, structural and functional changes in proteins, or even damage to nucleic acids. Literature data suggest that in different cases of induced oxidative stress under in vitro or in vivo conditions, $\mathrm{AKG}$, like some other metabolites of the Krebs cycle, has antioxidant properties (Andrae et al. 1985). AKG may participate in non-enzymatic oxidative decarboxylation during the decomposition of hydrogen peroxide, which is conditioned by its chemical structure (Long and Halliwell 2011; Sokołowska et al. 1999; Velvizhi et al. 2002a, b; Yamamoto and Mohanan 2003). It has also been shown that AKG can prevent damage to mitochondrial DNA induced by free radicals in mouse neural cells (Yamamoto and Mohanan 2003). Furthermore, AKG inhibited oxidative stress induced in vivo in rats by administration of ammonium acetate or ethanol (Velvizhi et al. 2002a, b). Additionally, it has been detected that AKG administration positively modulates antioxidant levels in rats during induced hepatocarcinogenesis, restoring antioxidants as well as antioxidative enzyme activity to almost normal levels (Dakshayani et al. 2006). In another 
in vivo study (Varma and Hegde 2004), AKG had a protective effect against oxidative stress-related cataract formation induced by injection of sodium selenite to rat pups.

One of the most interesting features of $A K G$ is its antagonist activity against cyanogens, i.e., materials containing nitriles from which human organism can generate free cyanide at a level that is toxic to the body. Cyanogens may occur naturally or they can be synthetically manufactured; they can be found in various industrial products, household utensils, or even in certain medications (Bhattacharya et al. 2009). Cyanide (hydrocyanic acid salt) is a rapidly acting neurotoxin, the operation of which is related to, among others, induction of oxidative stress in neurons, formation of ROS, and inhibition of the activity of a number of metalloenzymes including the antioxidant enzyme system (Ardelt et al. 1989, 1994; Muller and Krieglstein 1995; Solomonson 1981). The action of cyanide in the cell leads to impaired mitochondrial activity, as a result of which cellular respiration and energy metabolism is inhibited, which finally causes lactic acidosis and cell death (Bhattacharya et al. 2009; Hariharakrishnan et al. 2009). As has been shown, AKG acts as an antagonist of cyanide poisoning, and its protective effect involves, e.g., binding cyanide by a keto group attached to the carboxylic carbon of $\mathrm{AKG}$, which leads to formation of an intermediate_cyanohydrin (Moore et al. 1986; Norris et al. 1990). Furthermore, AKG prevented cyanide-induced reduction in the level of glutathione (an important antioxidant of the cell) and DNA fragmentation in rat thymocytes cultured in vitro (Bhattacharya et al. 2002). Moreover, AKG is known to have protected the brain and liver of rats from damage caused by cyanide-induced ROS activity, and the addition of sodium thiosulphate increased its protective effect (Tulsawani et al. 2005). It also showed the ability to neutralise the oxidative stress caused by cyanogens (Bhattacharya et al. 2009).

Recent studies have shown that the AKG molecule modulates the activity of antioxidant enzymes and stabilises the oxidation-reduction homeostasis in mice of advanced age to the level observed in young animals (Niemiec et al. 2011).

\section{AKG as a Complementary Factor in States of Protein Deficiency: Clinical and Animal Studies}

As a precursor of glutamine, $\mathrm{AKG}$ is a molecule with high potential in the treatment of states with increased protein catabolism, such as recovery after trauma, severe infections and burns, or after surgeries. In a number of independent clinical studies, attempts have been made to use exogenous AKG in alleviating this type of disorders by introducing supplementation mainly with an ornithine salt of alphaketoglutarate $(\mathrm{OKG})$, consisting of two molecules of ornithine and one molecule of AKG. It has been shown that such a combination is more efficient than AKG or ornithine alone in restoring glutamine pools in muscles (Cynober et al. 2007). The mechanism of OKG action in the body is still unclear, but it is probably multifactorial. OKG activity is associated with an increased synthesis of glutamine, proline, arginine, polyamines as well as with its capacity to induce secretion of anabolic hormones (insulin, growth hormone) and probably with elevated production of nitric oxide from arginine (Cynober 2004). Many studies (Coudray-Lucas et al. 2000; De Bandt et al. 1998; Donati et al. 1999; Hammarqvist et al. 1989, 1990, 1991; Wernerman et al. 1987) showed that OKG administered orally, enterally, or parenterally improved protein metabolism in patients with chronic or acute protein deficiency. Additionally, OKG administration improved nitrogen balance of the body and decreased protein catabolism by reducing muscle proteolysis in patients with severe burns (CoudrayLucas et al. 2000; De Bandt et al. 1998; Donati et al. 1999), after surgery (Hammarqvist et al. 1989, 1991; Wernerman et al. 1987), trauma, or acute infections (Coudray-Lucas et al. 2000; De Bandt et al. 1998; Donati et al. 1999; Hammarqvist et al. 1990). In patients with burns, administration of $\mathrm{OKG}$ also accelerated wound healing (CoudrayLucas et al. 2000; De Bandt et al. 1998; Donati et al. 1999). OKG also helped to restore metabolic balance by stimulating the secretion of anabolic hormones - insulin, growth hormone (GH), and insulin-like growth factor (IGF)-1 in patients after trauma (Jeevanandam and Petersen 1999). The introduction of OKG supplementation in malnourished patients of advanced age resulted in a significant improvement in their overall health expressed by increased appetite and improved motor skills; it also shortened the time of recovery after severe illnesses or surgery (BlondeCynober et al. 2003; Brocker et al. 1994).

Also, many studies on animals with induced muscle catabolism (Jeevanandam et al. 1996; Le Boucher et al. 1997; Ségaud et al. 2005; Vaubourdolle et al. 1988, 1991) showed that $\mathrm{OKG}$ modulated protein metabolism by decreasing urea excretion, increasing protein synthesis in the liver and the intestine, and by inhibiting the degradation of myofibrils, reducing total proteolysis, and loss of glutamine from muscle tissue. In addition, OKG exerted a positive effect on the functioning of the intestinal mucosa and contributed to its recovery after surgery (Czernichow et al. 1997; Dumas et al. 1988; Raul et al. 1995). Studies performed on rats have shown that $\mathrm{OKG}$ also improves motor skills in healthy individuals (Moinard et al. 2004). It is also known to protect liver cells against damage and prevent a decrease in the activity of the cytochrome P-450 family produced in liver (Roch-Arveiller et al. 1999). 
Moreover, recent studies have shown that AKG can alleviate intestinal mucosa injury under inflammatory conditions and enhance protein synthesis in intestinal epithelial cells (Hou et al. 2011; Yao et al. 2012).

\section{AKG as an Immunomodulatory Agent}

Glutamine is a known immunoenhancing nutrient in vivo and a modulator of immune cell growth and function in vitro (Abcouwer 2000; Andrews and Griffiths 2002; Saito et al. 1999; Ziegler and Daignault 2000). It modulates the function of monocytes and neutrophils (by increasing phagocytosis and ROS intermediate production) and macrophages (by enhancing cytokine production) involved in the early, non-specific defence response (Furukawa et al. 1997, 2000; Ogle et al. 1994; Wells et al. 1999). Additionally, glutamine is also a fuel for lymphocyte functions (Ardawi 1988) enhancing their proliferation and production of intracellular ROS and glutathione (Chang et al. 1999a) or cytokines (Chang et al. 1999b; Kew et al. 1999). It has been shown that AKG, as a glutamine homologue, has immune-enhancing properties as well, influencing both the non-specific and the specific immune response, especially in stress situations. Studies on rats with burn injures demonstrated that OKG (ornithine alpha-ketoglutarate) displays immunomodulatory properties, because it counteracted the decrease in superoxide anion $\left(\mathrm{O}_{2}^{-}\right)$generation in polymorphonuclear leukocytes (PMNs) from these animals (Roch-Arveiller et al. 1996). Moreover, in other in vivo studies, $\mathrm{OKG}$ enhanced the intracellular production of hydrogen peroxide $\left(\mathrm{H}_{2} \mathrm{O}_{2}\right)$ and $\mathrm{O}_{2}^{-}$in PMNs and monocytes isolated from rats with induced catabolism, which confirmed that OKG can improve phagocyte response during stress (Moinard et al. 1999, 2002). Additionally, it has been shown that OKG can enhance macrophage cytotoxicity in stress situations by restoring tumour necrosis factor- $\alpha$ secretion and increasing nitric oxide production in stimulated macrophages (Moinard et al. 1999, 2000). Also, exogenous AKG increased $\mathrm{O}_{2}^{-}$. and $\mathrm{H}_{2} \mathrm{O}_{2}$ intracellular production as well as myeloperoxidase activity in PMNs in vitro (Mühling et al. 2010). Furthermore, OKG counteracted thymic involution (which is classically associated with a decreased thymocyte count) in burn injured rats and increased tissue concentrations of glutamine and arginine, two essential nutrients for activated immune cells (Le Boucher et al. 1999). OKG can also stimulate various mechanisms of the immune system to an anti-tumour response. It was observed that $\mathrm{OKG}$ administered as a dietary supplement to rats with tumours increased the cytostatic activity of macrophages and the cytotoxic activity of natural killer cells (Robinson et al. 1999).

\section{The Influence of AKG on Bone Tissue}

In recent years, numerous papers (Dobrowolski et al. 2008; Filip et al. 2007; Filip 2007; Harrison et al. 2004; Radzki et al. 2012; Tatara et al. 2005, 2006, 2007) have been published to suggest that AKG may have an anabolic effect on bone tissue. Many in vivo studies (Harrison et al. 2004; Tatara et al. 2006, 2007) have demonstrated that supplementation of AKG or its derivatives during the animal growth has positive effects on the development of skeleton by improving the mechanical properties of skeletal bone. Moreover, other in vivo studies have shown that AKG supplementation prevented the development of osteopenia in female ovariectomized rats (Radzki et al. 2012), in rats after gastrectomy (Dobrowolski et al. 2008) or in model of osteopenia induced by denervation in turkeys (Tatara et al. 2005). In a study of menopausal women, it was also observed that administration of AKG (with Ca) inhibited bone resorption and reduced the effects of osteopenia. In women treated with AKG sodium salt, after 24 weeks of treatment, a significant decrease (about $37 \%$ ) in the level of CTX in the bloodstream was observed as well as higher bone density of the lumbar spine in comparison with the control group (receiving only $\mathrm{CaCO}_{3}$ ) (Filip et al. 2007). The results of above studies suggest that AKG not only can inhibit bone resorption, but can also induce reconstruction of bone tissue in the states of osteopenia and osteoporosis.

Although the positive influence of AKG on bone mineral density and strength is well documented in many in vivo studies (Dobrowolski et al. 2008; Filip et al. 2007; Harrison et al. 2004; Radzki et al. 2012; Tatara et al. 2005, 2006, 2007), its mechanism has not been elucidated so far. It is believed that AKG can contribute to an increase in the body pool of amino acids necessary for synthesis of type I collagen (proline and hydroxyproline) and thus have a positive effect on bone quality (Harrison and Pierzynowski 2008; Majamaa et al. 1987; Petersen et al. 2003). Some of the results of studies conducted in vivo in humans and animals (Cynober et al. 1990; Jeevanandam and Petersen 1999; Kristensen et al. 2002; Riedel et al. 1996; Tatara et al. 2005, 2006), where it was observed that OKG or AKG sodium salt led to an increase in the serum levels of proline, may be used as a support of this thesis. It is also suggested that AKG can stimulate production of IGF-1 or $\mathrm{GH}$, which are anabolic hormones that regulate bone modelling and remodelling. IGF-1 increases the efficiency of mature osteoblasts by, among others, stimulating collagen synthesis and inhibiting degradation thereof, while GH stimulates proliferation of the osteoblastic cell line and increases the expression of bone morphogenetic proteins, which stimulate osteoblast differentiation and bone formation (Giustina et al. 2008). Moukarzel et al. (1994) 
showed that parenteral administration of $\mathrm{OKG}$ increased the circulating plasma level of IGF-1, which was confirmed by another study (Jeevanandam and Petersen 1999) carried out on grown-ups who were orally supplemented with OKG and in whose circulating blood the levels of IGF-1 and $\mathrm{GH}$ were increased. Furthermore, it was demonstrated (Tatara et al. 2012) that oral administration of AKG in combination with beta-hydroxy-beta-methylbutyrate for pregnant sows increased the serum concentration of $\mathrm{GH}$ and IGF-1 in their offspring. However, in the studies of Harrison et al. (2004), in which a group of lambs were supplemented with sodium salt of $\mathrm{AKG}$, no increase in IGF-1 plasma levels was observed, yet there was an increase in their bone mineral density. In turn, other in vivo studies (Harrison et al. 2004; Rosen et al. 1995) have demonstrated that IGF-1 stimulates bone growth and increases their size, but does not affect the mineral density. These findings suggest that the positive effect of AKG on bone tissue is probably not associated with stimulation of IGF-1 and GH production when it is administered alone.

The positive effect of AKG on bone tissue may be due to its important role in the biosynthesis of glutamate and glutamine, as well as a multidirectional impact on the synthesis of type I collagen, the main protein of the bone matrix. AKG can participate in the metabolism of bone collagen by various mechanisms. First of all, this metabolite regulates the activity of enzyme $\mathrm{P} 4 \mathrm{H}$, as mentioned above, a member of the 2-OGDDs family, commonly present in various types of cells. $\mathrm{P} 4 \mathrm{H}$ occurs inside the endoplasmic reticulum and controls the synthesis of collagen by hydroxylation of proline to 4-hydroxyproline (Hutton et al. 1966; Kivirikko and Pihlajaniemi 1998), which is necessary to form a triple helix of the collagen molecule. Incomplete hydroxylation of proline in the Gly$\mathrm{X}-\mathrm{Y}$ sequence results in incorrect formation of the collagen triple helix. Such defective collagen molecules, contrary to the proper ones, are degraded in the endoplasmic reticulum instead of being secreted into the cytoplasm (Lamandé and Bateman 1999; Myllyharju 2003). AKG can also participate in the biosynthesis of collagen by increasing the pool of proline, an amino acid that is the main component of the collagen molecule. The primary source of proline used for biosynthesis of collagen are the products of endogenous and exogenous collagen degradation (Jackson et al. 1975). Proline may also be formed by conversion of $\mathrm{AKG}$ to glutamate, and then to pyrroline-5-carboxylate (P5C), which is converted directly into proline (Smith et al. 1980). However, this pathway is less important in acquiring a pool of proline needed for collagen biosynthesis. It is more important that its precursor, i.e. P5C affects the activity of prolidase, an enzyme responsible for cleavage of dipeptides containing C-terminal proline or hydroxyproline and thereby creating a pool of amino acids required for the biosynthesis of collagen (Myara et al. 1984). Karna et al. (2001) have shown in their study that P5C indeed stimulates the production of collagen through activation of prolidase. Therefore, as a precursor of P5C, AKG can significantly affect the metabolism of proline. The contribution of $\mathrm{AKG}$ in the biosynthesis of collagen was confirmed in in vitro studies, in which it stimulated the synthesis of procollagen in human skin fibroblasts by increasing the activity of prolidase (Son et al. 2007). Additionally, in vivo studies (Son et al. 2007) have demonstrated a protective effect of AKG on UVB-irradiated skin, since administration thereof to the skin of mice irradiated with UVB reduced the number of wrinkles and decreased the degree of collagen fibre destruction in the skin.

\section{AKG as an Anticancer Agent}

So far, not many investigations of the anticancer activity of AKG have been carried out (Brière et al. 2005; Hou et al. 2014; MacKenzie et al. 2007; Matsumoto et al. 2006, 2009; Robinson et al. 1999; Rzeski et al. 2012; Tennant et al. 2009). However, the results of those few available papers suggest anti-tumour properties of AKG under both normal and reduced oxygen levels and interference of its activity with various mechanisms.

\section{The Role of AKG in the Regulation of HIF-1 Activity}

Recent research suggests that AKG and its structural analogues (succinate, fumarate) are involved in the regulation of signalling pathways engaged in promotion of carcinogenesis (for review see Raimundo et al. 2011).

PHDs 1-3 which catalyse the hydroxylation of proline residues are very important enzymes belonging to the 2-OGDD group. They are known to regulate the activity of HIFs, which play a major role in carcinogenesis, inducing changes in the metabolism of cancer cells (Bruick and McKnight 2001; Epstein et al. 2001; Hirsilä et al. 2003; Jaakkola et al. 2001; Maxwell et al. 2001). The best characterised enzyme of this group is PHD2 (prolyl hydroxylase domain-containing protein 2), encoded by the gene EGLN1, which is proposed to be the most important in the hypoxic response under normoxia (Appelhoff et al. 2004; Berra et al. 2003; Schofield and Ratcliffe 2005). AKG-dependent dioxygenases can potentially be sensitive to the slightest changes in cellular concentrations of this metabolite. This is related to the fact that the Michaelis constant $\left(K_{\mathrm{m}}\right)$ of $\mathrm{AKG}$ for many dioxygenases is similar to the physiological concentration of this ketoacid (Clifton et al. 2006; Loenarz and Schofield 2008). In addition, the 
enzymes responsible for the formation of AKG (IDH-1, -2, -3 ), and for its further processing (AKG dehydrogenase, glutamate dehydrogenases) are strictly controlled.

During the development of solid tumours, large areas with considerable hypoxia are formed. In response to hypoxia, there is a change in the metabolism of cancer cells, enabling them to survive and adapt to the changed, highly stressful microenvironment. Metabolic changes include, among others, intensified glycolysis, increased glycogen synthesis, and use of glutamine (rather than glucose) as the primary substrate for fatty acid synthesis. This metabolic reprogramming is directed at the transcriptional level by the transcription factor HIF-1, which also induces the expression of genes regulating the process of angiogenesis and cell proliferation (Semenza 2013).

There are two types of HIF (HIF-1 and HIF-2) in mammalian cells. Each of them is a heterodimer consisting of one subunit $\alpha$, which is $\mathrm{O}_{2}$-labile, and one stable subunit $\beta$. There are three known isoforms of subunit $\alpha$ : HIF- $1 \alpha$, HIF- $2 \alpha$, and HIF-3 2 . The first one (HIF-1 $\alpha$ ) is constitutively expressed in all cells, while the other two isoforms (HIF-2 $\alpha$ and HIF-3 $\alpha$ ) are expressed only in certain tissues (including endothelial, lung, renal, and liver cells, as well as the cells of the myeloid lineage). The HIF-3 $\alpha$ subunit functions as a dominant negative regulator of HIF- $2 \alpha$ and HIF- $1 \alpha$, because by binding to subunit $\beta$, it blocks its binding to DNA (Kaelin and Ratcliffe 2008; Maynard et al. 2005; Wiesener et al. 2003). Under aerobic conditions, proline residues (Pro402 and Pro564) located in the oxygen-dependent degradation domain of HIF-1 $\alpha$ are hydroxylated by PHD2, which results in recognition of the subunit by the VHL protein (von Hippel-Lindau tumour suppressor), a part of the ubiquitin ligase complex E3. Then, after poly-ubiquitination, HIF-1 $\alpha$ is rapidly degraded in the proteasome (Ivan et al. 2001; Kaelin 2005; Yu et al. 2001). Under the oxygen deficiency conditions or at reduced levels of $\mathrm{AKG}$ or $\mathrm{Fe}^{2+}$, the hydroxylation reaction involving PHD2 slows down or stops, resulting in HIF-1 $\alpha$ accumulation in the cytoplasm (Schofield and Ratcliffe 2005). After the translocation into the cell nucleus, HIF-1 $\alpha$ dimerises with a stable HIF-1 $\beta$ subunit and the dimer recognises and binds to hypoxia response elements in the genome (Kaelin 2005).

\section{The Role of Defects in the Krebs Cycle Enzymes in the Regulation of HIF-1 Activity}

As mentioned above, under physiological conditions, HIF1 is activated by hypoxia. However, this factor may also be activated in normal oxygen access, and activation of the HIF-1-mediated response pathway in such conditions is referred as pseudohypoxia. Stabilisation of the HIF-1 $\alpha$ subunit occurs, e.g., in the case of a deletion or inactivating mutation in the gene for the VHL protein, which determines the development of tumours, such as human glioblastoma or sporadic renal cell carcinoma (Latif et al. 1993; Ohh 2006; Pugh and Ratcliffe 2003). Also, mutations in the genes for enzymes involved in the metabolism of AKG, which is a cofactor of PHDs, result in stabilisation of the HIF-1 $\alpha$ subunit. These mutations occur mainly in three enzymes of the Krebs cycle: SDH, FH, and IDH.

$\mathrm{SDH}$ is a heterotetramer complex localised in mitochondria and composed of subunits A, B, C, and D and the SDH5 factor involved in tetramer mounting (Hao et al. 2009). It has been demonstrated that mutations occurring in the individual components of the complex may predispose to the development of certain types of cancer, mainly paragangliomas (Astuti et al. 2001; Baysal et al. 2000, 2002; Burnichon et al. 2010; Niemann and Muller 2000), pheochromocytomas (Astuti et al. 2001), renal cell carcinoma (Ricketts et al. 2008; Vanharanta et al. 2004), T cell acute leukaemia (Baysal 2007), and gastrointestinal stromal tumours (Italiano et al. 2012; Janeway et al. 2011; Stratakis and Carney 2009). FH, on the other hand, is an active homotetramer occurring in the mitochondria and the cytoplasm, recessive mutations in the gene of which are the cause of development of encephalopathy and early death, while its dominant mutations predispose to cancers such as multiple cutaneous and uterine leiomyomas or hereditary leiomyomatosis and renal cell cancer (Castro-Vega et al. 2014; King et al. 2006; Tomlinson et al. 2002). Defects in the SDH and FH enzymes are the cause of accumulation of Krebs cycle intermediates, i.e., succinate and fumarate (structural analogues of AKG) in cells. These compounds compete with AKG in binding to PHD2, and when bound to the enzyme they inhibit its activity, which in turn contributes to stabilisation of HIF- $1 \alpha$ and activation of genes that promote carcinogenesis (Brière et al. 2005; Isaacs et al. 2005; Pollard et al. 2005; Pugh and Ratcliffe 2003; Selak et al. 2005).

Mutations in the genes of IDH1 and IDH2 may also affect the activity of HIF-1 (Zhao et al. 2009). NADP ${ }^{+}$ dependent enzymes, IDH1 and IDH2, are homodimers, wherein IDH1 is present in the cytoplasm and peroxisomes, and IDH2 in cell mitochondria (Corpas et al. 1999). It has been shown that mutations in IDH1 and IDH2 are responsible for the development of certain cancer types, including diffuse and anaplastic gliomas, secondary glioblastomas, specific types of cartilaginous tumours, and acute myeloma leukaemia (for review see Dang et al. 2010; Schaap et al. 2013). The mutated enzymes lose their natural ability to transform isocitrate into $\mathrm{AKG}$, instead acquiring the ability to reduce AKG to $2 \mathrm{HG}$. As a result, the pool of mobile $\mathrm{AKG}$ is reduced, and the cell accumulates its structural analogue-2HG (Dang et al. 2009; Schaap et al. 2013). According to some authors' reports, both a 
reduction in the amount of $\mathrm{AKG}$ and an increase in the amount of $2 \mathrm{HG}$ can inhibit the activity of PHD2 and activate HIF-1 (Xu et al. 2011; Zhao et al. 2009). Some contradictory reports suggest in turn that the $R$-enantiomer of 2HG stimulates the activity of EGLN1 (PHD2), EGLN2 (PHD1), and to a lesser extent EGLN3 (PHD3) and thus inhibit the activity of factor HIF-1. In contrast, the $S$ enantiomer of $2 \mathrm{HG}$ has the capability of inhibiting PHDs (Koivunen et al. 2012; Losman et al. 2013). However, recent studies (Tarhonskaya et al. 2014) have shown that under in vitro conditions, non-enzymatic oxidation of $2 \mathrm{HG}$ to $\mathrm{AKG}$ may occur (involving reducing agents such as ascorbic acid or the reduced form of L-glutathione), and the level of AKG formed in this process is sufficient to activate PHD2. The results of these studies may suggest a misinterpretation of the previous results (Koivunen et al. 2012), but further studies are needed to determine accurately the effect of $2 \mathrm{HG}$ on the activity of PHD2.

\section{The Role of AKG and its Structural Analogues in the Regulation of Epigenetic Processes}

Chemical modifications of chromatin play an important role in regulating the function of the genome and therefore, in cell physiology. Information provided by epigenetic modifications (changes made without modifying the DNA sequence) plays a considerable part in regulating the processes such as transcription or DNA repair and replication. At the same time, the role of factors regulating epigenetic processes is also very important, because changes in the level of their expression or genomic changes in these factors may contribute to induction or maintenance of a variety of tumours (Dawson and Kouzarides 2012). The basic processes regulating chromatin structure and function are DNA methylation and histone post-translational modification (acetylation, methylation, phosphorylation, ubiquitination, biotinylation, and SUMOylation). Many enzymes, including methyltransferases and demethylases, are involved in these processes (Meng et al. 2015). Recent studies indicate that $\mathrm{AKG}$ and its structural analoguessuccinate, fumarate, and $2 \mathrm{HG}$ can regulate the level of DNA and histone methylation, as the main enzymes conducting demethylation/hydroxylation reactions belong to the family of 2-OGDD. The main demethylases of histones are KDM2-7, which remove methyl groups from almost all known methylation sites in histones and can also catalyse the demethylation of three methylated lysines and arginines (Hoffmann et al. 2012). In turn, the process of oxidative DNA demethylation is conducted by TET1-3 hydroxylases, which hydroxylate $5 \mathrm{mC}$ to 5 -hmC (Ito et al. 2010; Tahiliani et al. 2009). Several studies (Cervera et al. 2009; Chowdhury et al. 2011; Letouzé et al. 2013; Schaap et al. 2013; Xiao et al. 2012; Xu et al. 2011) have shown that both the Krebs cycle intermediate metabolites, succinate and fumarate, and the $R(-) 2 \mathrm{HG}$ act as competitive inhibitors of enzymes KDMs and TETs, and that the inhibitory effect enhances methylation of DNA and histones by methyltransferases, which in turn may increase carcinogenesis. Nevertheless, the effect of these structural analogues of $\mathrm{AKG}$ can be reversed by $\mathrm{AKG}$ itself.

\section{Anti-Tumour Activity of Exogenous AKG: In Vitro and In Vivo Studies}

One of the very important elements of response to hypoxia and HIF-1 activation is transcription of genes playing a key role in angiogenesis. This process is crucial for the development of solid tumours. The growing tumour tissue needs high amounts of oxygen and nutrients that are supplied by diffusion from the nearby blood vessels in the initial stage of tumour development. As the tumour develops and increases its size, the cells of the nearby blood vessels start running out of oxygen, which activates HIF-1 and initiates the process of neoangiogenesis. HIF-1 in tumour cells activates the transcription of genes for proangiogenic factors such as vascular endothelial growth factor (VEGF), PDGF-B (platelet-derived growth factor, type B), hepatocyte growth factor, epidermal growth factor, angiopoietin-2, or placental growth factor (Sacewicz et al. 2009). Matsumoto et al. (2006, 2009) showed that exogenous AKG exhibited anti-tumour activity by reducing the level of the HIF-1 $\alpha$ subunit and inhibition of angiogenesis in hypoxic conditions. In their study, AKG inhibited the expression of the HIF-1 $\alpha$ subunit and the ability to connect HIF-1 protein subunits, decreased the activity of the Vegf gene promoter, and, consequently, inhibited VEGF and erythropoietin production in the Hep3B cell line. Furthermore, AKG inhibited tube formation in an in vitro angiogenesis model. Those antiangiogenic effects of AKG were confirmed in another in vitro study, carried out using the Lewis lung carcinoma (LLC) cell line (Matsumoto et al. 2009). Additionally, AKG administered alone showed anti-tumour activity and enhanced the activity of a chemotherapeutic agent (5-fluorouracil, 5-FU) in vivo. In the mouse dorsal air sac assay, AKG reduced the amount of newly formed blood vessels caused by administration of the cancer cell line (LLC). Also intraperitoneal administration of AKG alone or its combination with 5-FU to mice with transplanted tumours significantly inhibited tumour growth and angiogenesis in tumour tissue (Matsumoto et al. 2009) which suggests the clinical usefulness of this molecule. In turn, the results of the experiments carried out by Brière et al. (2005) and MacKenzie et al. (2007) suggest a possibility of application of $\mathrm{AKG}$ in the treatment of neoplastic diseases in which Krebs cycle enzyme defects cause pseudohypoxia and 
activation of HIF-1 in normoxia. Brière et al. (2005) have shown that exogenous AKG prevented translocation of HIF-1 into the nucleus of fibroblasts with a mutation in the gene for SDHA (succinate dehydrogenase subunit A). In another study, the MacKenzie et al. (2007) have shown that the competitive inhibition of PHDs by succinate or fumarate may be reversed by increasing the cellular level of AKG. However, native AKG does not easily penetrate into cells; therefore, to increase the effectiveness of its function, tests were carried out using cell-permeating AKG derivatives, i.e. AKG esters with increased hydrophobicityoctyl-AKG and 1-trifluoromethyl benzyl-AKG (converted by cytoplasmic esterases to AKG). These derivatives restored the normal activity of PHDs, thereby decreasing the level of HIF-1 $\alpha$ in SDH-deficient cells (MacKenzie et al. 2007). Other in vitro studies (Tennant et al. 2009) have shown that AKG esters (1-trifluoromethyl benzylAKG, TaAKG) can restore the activity of PHDs under hypoxic conditions, which has far-reaching effects on tumour cells. Restoration of the PHD activity in such conditions not only resulted in destabilisation of HIF- $1 \alpha$, but also induced functional changes in cells-reversal of the hypoxia-induced increased glycolysis process and cell death as its consequence. In addition, it has been shown that AKG derivatives (TaAKG and ETAKG-5-ethyl,4-1trifluoromethylbenzyl AKG) may also function well in vivo. TaAKG penetrated several layers of cells in spheroids derived from cell line HCT116 (human colon carcinoma) and destabilised their HIF- $1 \alpha$ subunit. Moreover, after oral administration of ETAKG to a mouse xenograft tumour model, increased levels of AKG within the tumour tissues were observed, as well as decreased levels of HIF- $1 \alpha$, and reduced glucose metabolism. The results of the studies mentioned above suggest that AKG in the form of a diester can reactivate PHDs and destabilise HIF- $1 \alpha$ in vivo, thereby reducing the expression of genes targeted by this factor (Tennant et al. 2009). However, it has recently been shown that not all types of AKG esters that penetrate the cell membrane have the same activity on HIF-1. In the studies of Hou et al. (2014), membrane permeable ester dimethyl AKG (DAKG), which is the precursor of AKG, temporarily stabilized HIF- $1 \alpha$ by inhibition of PHD2. During the long-term impact of DAKG on cells under normoxia conditions, an increase in the level of HIF- $1 \alpha$ and expression of its target genes was observed, which indicates that DAKG, in contrast to $\mathrm{AKG}$, promotes the state of pseudohypoxia. The authors speculate that at a high availability of nutrients, DAKG may have been quickly converted to succinate or fumarate, which inhibited the activity of PHD2. On the other hand, the activity of PHD2 might have been inhibited by increasing intracellular levels of ROS in pseudohypoxic conditions induced by DAKG.
Additionally, in vitro studies have shown that exogenous AKG may affect the level of DNA methylation (Letouzé et al. 2013). In contrast to genetic mutations, DNA methylation is a reversible process, which creates a possibility of introduction of new drugs for the treatment of certain tumours (Rodríguez-Paredes and Esteller 2011). Cancer cells are often characterised by a decrease in total DNA methylation and by hypermethylation of promoter $\mathrm{CpG}$ islands, which results in transcriptional silencing of tumour suppressor genes. This phenotype, which is characterised by simultaneous multiple gene hypermethylation, occurs, for example, in glioma, in which it is the result of mutations in IDH1/IDH2 genes and the inhibiting activity of $2 \mathrm{HG}$ on enzymes belonging to the KDM and TET groups. Also in paraganglioma, mutations in the SDH genes determine such a phenotype (Letouzé et al. 2013). In the studies of Letouzé et al. (2013), SDH-deficient chromaffin cells displayed an increased 5-mC/5-hmC ratio and histone methylation, while the addition of AKG to the culture medium reversed the accumulation of $5 \mathrm{mC}$ in vitro and consequently changed this phenotype. These results suggest that exogenous AKG can restore the TETs enzyme activity inhibited by succinate accumulated in cells and restore the cellular normal phenotype.

Given the contradictory results obtained in studies using various esters of AKG, currently, it seems to be safer to use AKG in its native form in cancer therapy. This is supported by the fact that recent studies have shown an antiproliferative effect of AKG on three cancer cell lines: Caco-2, HT29, and LS-180, representing different stages of the development of colon adenocarcinoma (Rzeski et al. 2012). AKG interfered in the cell cycle of the tumour cells by increasing the expression of cyclin-dependent kinase (CDK) inhibitors p21 Waf/CIP1 and p27 Kip1. Affecting the cell cycle by influencing the proteins involved in its regulation (cyclins) is a very promising feature of AKG as a potential anticancer agent. Each stage of the cell cycle is supported by specific cyclins forming complexes with CDKs, which are involved in phosphorylation of certain proteins. This facilitates maintenance of the cycle, and consequently leads to cell division. The above-mentioned CDK inhibitors subsequently inhibit DNA replication and are responsible for cell cycle arrest resulting in the absence of cell division (Meeran and Katiyar 2008; Xiong et al. 1993). The influence of AKG on the cell cycle of tumour cells is not limited to increasing the expression of the CDK inhibitors. It also decreased the protein level of cyclin D1 and inhibited phosphorylation of the key regulator of the cell cycle, i.e., the $\mathrm{Rb}$ protein, which resulted in arresting a large number of cells in the G1 phase, preventing them from entering the division phase (Rzeski et al. 2012).

It should be noted that AKG in combination with 5-hydroxymethylfurfural, prepared in the form of an 
infusion solution, are currently being investigated for the treatment of patients with non-small-cell lung carcinoma, not responding to any conventional therapy. This combination, named $\mathrm{KARAL}^{\circledR}$, is currently in phase II clinical study and shows great promises as cancer treatment (Donnarumma et al. 2013).

\section{Conclusions}

Since the discovery and description of the Krebs cycle, a number of features and functions of one of its main metabolites, i.e. AKG have been identified so far. Yet, many of the AKG actions are still waiting to be discovered. However, current knowledge about this metabolite already ensures its practical application in various fields of human life. Today, AKG is synthesised chemically, but attempts have been made at biotechnological production of this metabolite by various bacteria and yeast (Otto et al. 2011). $\mathrm{AKG}$ is of particular importance in industry, where it is used as a building material in the chemical synthesis of heterocycles. It is also a major component of new biodegradable, chemoselective, and mechanically adjustable elastomers with a potential application in biomedicine (Barrett and Yousaf 2008). However, the properties of this molecule also allow use thereof in medicine. AKG is used nowadays as a component of solutions for infusion, formulations used in wound healing, or as a dietary supplement. It is used, for example, during cardiac operations in order to avoid disturbances of blood flow and pressure (Kjellman et al. 1997) or in patients after surgery or trauma to prevent muscle breakdown. Many studies indicate that it may be helpful in the treatment of various diseases and solving health problems, e.g., kidney disorders, bacterial and yeast infections, problems with many organs, such as the intestines, stomach, liver, eyes, and even during cyanide intoxication. However, the efficiency of the therapeutic use, in some cases, is still debated. Broadly described, the positive effect of $\mathrm{AKG}$ on bone tissue suggests its potential application in prevention of bone formation disorders, in the treatment of diseases with progressive loss of bone mass, such as osteoporosis, or in improving the body's bone mass. Nevertheless, the mechanism of its action on bone tissue has not been elucidated yet.

Some studies from recent years have provided a lot of new interesting information about the role of $\mathrm{AKG}$ as a molecule regulating cell function, which may allow it to be used in the treatment of cancer. Depending on the type of cancer, AKG could affect tumour cells by reversing their metabolic response to hypoxia or pseudohypoxia. The antiproliferative activity of AKG suggests in turn the possibility of restoring oxidative phosphorylation in tumour cells in place of aerobic glycolysis, which is characteristic to all cancers, in states of increased availability of this metabolite to tumour cells. However, additional studies are required to confirm this hypothesis. Additionally, for the therapeutic efficacy of $\mathrm{AKG}$, it is also important to determine which form of supplementation would be the most applicable-oral administration, infusion, or, e.g., administration of $\mathrm{AKG}$ in the form of nanomolecules whose action is aimed specifically at the tumour cells. Not until performing additional in vitro studies and clinical trials could we evaluate the effectiveness of AKG as an anticancer agent then. Nevertheless, even the results of the already existing studies suggest a possibility of using AKG, e.g., in chemoprevention or as a support to anti-cancer therapy.

Recent studies suggest that AKG can also regulate the ageing process of the organism and have an influence on prolonging the lifespan (Chin et al. 2014; Salminen et al. 2014). Research performed in the next few years will probably give us an answer to the question whether to expand the characteristics of AKG with another feature, which is maintaining the longevity.

Acknowledgments This work was supported by research Grant No 2013/11/B/NZ4/04557 from State Funds for Scientific Research National Science Centre (NCN), Poland.

Open Access This article is distributed under the terms of the Creative Commons Attribution 4.0 International License (http:// creativecommons.org/licenses/by/4.0/), which permits unrestricted use, distribution, and reproduction in any medium, provided you give appropriate credit to the original author(s) and the source, provide a link to the Creative Commons license, and indicate if changes were made.

\section{References}

Abcouwer SF (2000) Effects of glutamine on immune cells. Nutrition 16:67-69

Al Balushi RM, Cohen J, Banks M et al (2013) The clinical role of glutamine supplementation in patients with multiple trauma: a narrative review. Anaesth Intensive Care 41:24-34

Amary MF, Bacsi K, Maggiani F et al (2011) IDH1 and IDH2 mutations are frequent events in central chondrosarcoma and central and periosteal chondromas but not in other mesenchymal tumours. J Pathol 224:334-343

Andrae U, Singh J, Ziegler-Skylakakis K (1985) Pyruvate and related alpha-ketoacids protect mammalian cells in culture against hydrogen peroxide-induced cytotoxicity. Toxicol Lett 28:93-98

Andrews FJ, Griffiths RD (2002) Glutamine: essential for immune nutrition in the critically ill. Br J Nutr 87(Suppl 1):S3-S8

Appelhoff RJ, Tian YM, Raval RR et al (2004) Differential function of the prolyl hydroxylases PHD1, PHD2, and PHD3 in the regulation of hypoxia-inducible factor. $\mathrm{J}$ Biol Chem 279:38458-38465

Ardawi MS (1988) Glutamine and glucose metabolism in human peripheral lymphocytes. Metabolism 37:99-103 
Ardelt BK, Borowitz JL, Isom GE (1989) Brain lipid peroxidation and antioxidant protectant mechanism following acute cyanide intoxication. Toxicology 56:147-154

Ardelt BK, Borowitz JL, Maduh EU et al (1994) Cyanide induced lipid peroxidation in different organs: subcellular distribution and hydroperoxide generation in neuronal cells. Toxicology $89: 127-137$

Askanazi J, Carpentier YA, Michelsen CB et al (1980) Muscle and plasma amino acids following injury. Influence of intercurrent infection. Ann Surg 192:78-85

Astuti D, Latif F, Dallol A et al (2001) Gene mutations in the succinate dehydrogenase subunit SDHB cause susceptibility to familial pheochromocytoma and to familial paraganglioma. Am J Hum Genet 69:49-54

Aussel C, Coudray-Lucas C, Lasnier E et al (1996) Alpha-Ketoglutarate uptake in human fibroblasts. Cell Biol Int 20:359-363

Barrett DG, Yousaf MN (2008) Poly(triol $\alpha$-ketoglutarate) as biodegradable, chemoselective, and mechanically tunable elastomers. Macromolecules 41:6347-6352

Baysal BE (2007) A recurrent stop-codon mutation in succinate dehydrogenase subunit B gene in normal peripheral blood and childhood T-cell acute leukemia. PLoS One 2:e436

Baysal BE, Ferrell RE, Willett-Brozick JE et al (2000) Mutations in SDHD, a mitochondrial complex II gene, in hereditary paraganglioma. Science 287:848-851

Baysal BE, Willett-Brozick JE, Lawrence EC et al (2002) Prevalence of SDHB, SDHC, and SDHD germline mutations in clinic patients with head and neck paragangliomas. J Med Genet 39:178-183

Berra E, Benizri E, Ginouvès A et al (2003) HIF prolyl-hydroxylase 2 is the key oxygen sensor setting low steady-state levels of HIF1alpha in normoxia. EMBO J 22:4082-4090

Bhattacharya R, Lakshmana Rao PV, Vijayaraghavan R (2002) In vitro and in vivo attenuation of experimental cyanide poisoning by $\alpha$-ketoglutarate. Toxicol Lett 128:185-195

Bhattacharya R, Satpute RM, Hariharakrishnan J et al (2009) Acute toxicity of some synthetic cyanogens in rats and their response to oral treatment with alpha-ketoglutarate. Food Chem Toxicol 47:2314-2320

Biolo G, Fleming RY, Maggi SP et al (2000) Inhibition of muscle glutamine formation in hypercatabolic patients. Clin Sci 99:189-194

Blonde-Cynober F, Aussel C, Cynober L (2003) Use of ornithine $\alpha$ ketoglutarate in clinical nutrition of elderly patients. Nutrition 19:73-75

Borger DR, Tanabe KK, Fan KC et al (2012) Frequent mutation of isocitrate dehydrogenase (IDH) 1 and IDH2 in cholangiocarcinoma identified through broad-based tumor genotyping. Oncologist 17:72-79

Brière JJ, Favier J, Bénit $P$ et al (2005) Mitochondrial succinate is instrumental for HIF1alpha nuclear translocation in SDHAmutant fibroblasts under normoxic conditions. Hum Mol Genet 14:3263-3269

Brocker P, Vellas B, Albarede JL et al (1994) A two-centre, randomized, double-blind trial of ornithine oxoglutarate in 194 eldery, ambulatory, convalescent subjects. Age Ageing 23:303-306

Brugnara L, Vinaixa M, Murillo S et al (2012) Metabolomics approach for analyzing the effects of exercise in 13 subjects with type 1 diabetes mellitus. PLoS One 7:e40600

Bruick RK, McKnight SL (2001) A conserved family of prolyl-4hydroxylases that modify HIF. Science 294:1337-1340

Burnichon N, Brière JJ, Libé R et al (2010) SDHA is a tumor suppressor gene causing paraganglioma. Hum Mol Genet 19:3011-3020
Castro-Vega LJ, Buffet A, De Cubas AA et al (2014) Germline mutations in FH confer predisposition to malignant pheochromocytomas and paragangliomas. Hum Mol Genet 23:2440-2446

Cervera AM, Bayley JP, Devilee P et al (2009) Inhibition of succinate dehydrogenase dysregulates histone modification in mammalian cells. Mol Cancer 8:89

Chang WK, Yang KD, Shaio MF (1999a) Lymphocyte proliferation modulated by glutamine: involved in the endogenous redox reaction. Clin Exp Immunol 117:482-488

Chang WK, Yang KD, Shaio MF (1999b) Effect of glutamine on Th1 and Th2 cytokine responses of human peripheral blood mononuclear cells. Clin Immunol 93:294-301

Chappell JB (1968) Systems used for the transport of substrates into mitochondria. Br Med Bull 24:150-157

Chin RM, Fu X, Pai MY et al (2014) The metabolite $\alpha$-ketoglutarate extends lifespan by inhibiting ATP synthase and TOR. Nature 510:397-401

Chowdhury R, Yeoh KK, Tian YM et al (2011) The oncometabolite 2-hydroxyglutarate inhibits histone lysine demethylases. EMBO Rep 12:463-469

Clifton IJ, McDonough MA, Ehrismann D et al (2006) Structural studies on 2-oxoglutarate oxygenases and related doublestranded beta-helix fold proteins. J Inorg Biochem 100:644-669

Corpas FJ, Barroso JB, Sandalio LM et al (1999) Peroxisomal NADPdependent isocitrate dehydrogenase. Characterization and activity regulation during natural senescence. Plant Physiol 121:921-928

Coudray-Lucas C, Le Bever H, Cynober L et al (2000) Ornithine alpha-ketoglutarate improves wound healing in severe burn patients: a prospective randomized double-blind trial versus isonitrogenous control. Crit Care Med 28:1772-1776

Cynober L (2004) Ornithine alpha-ketoglutarate as a potent precursor of arginine and nitric oxide: a new job for an old friend. J Nutr 134:2858S-2862S

Cynober L, Vaubourdolle M, Dore A et al (1984) Kinetics and metabolic effects of orally administered ornithine alpha-ketoglutarate in healthy subjects fed with a standardized regimen. Am J Clin Nutr 39:514-519

Cynober L, Coudray-Lucas C, De Bandt JP et al (1990) Action of ornithine a-ketoglutarate, ornithine hydrochloride and calcium a-ketoglutarate on plasma amino acid and hormonal patterns in healthy subjects. J Am Coll Nutr 9:2-12

Cynober L, Lasnier E, Le Boucher J et al (2007) Effect of ornithine alpha-ketoglutarate on glutamine pools in burn injury: evidence of component interaction. Intensive Care Med 33:538-541

Czernichow B, Nsi-Emvo E, Galluser M et al (1997) Enteral supplementation with ornithine $\alpha$-ketoglutarate improves the early adaptive response to resection. Gut 40:67-72

Dąbek M, Kruszewska D, Filip R et al (2005) $\alpha$-ketoglutarate (AKG) absorption from pig intestine and plasma pharmacokinetics. J Anim Physiol Anim Nutr 89:419-426

Dakshayani KB, Subramanian P, Manivasagam T et al (2006) Metabolic normalization of alpha-ketoglutarate against $\mathrm{N}$-nitrosodiethylamine-induced hepatocarcinogenesis in rats. Fundam Clin Pharmacol 20:477-480

Dang L, White DW, Gross S et al (2009) Cancer-associated IDH1 mutations produce 2-hydroxyglutarate. Nature 462:739-744

Dang L, Jin S, Su SM (2010) IDH mutations in glioma and acute myeloid leukemia. Trends Mol Med 16:387-397

Dawson MA, Kouzarides T (2012) Cancer epigenetics: from mechanism to therapy. Cell 150:12-27

De Bandt JP, Coudray-Lucas C, Lioret N et al (1998) A randomized controlled trial of the influence of the mode of enteral ornithine $\alpha$-ketoglutarate administration in burned patients. J Nutr 128:563-569 
Dobrowolski PJ, Piersiak T, Surve VV et al (2008) Dietary alphaketoglutarate reduces gastrectomy-evoked loss of calvaria and trabecular bone in female rats. Scand J Gastroent 43:551-558

Donati L, Ziegler F, Pongelli G et al (1999) Nutritional and clinical efficacy of ornithine alpha-ketoglutarate in severe burn patients. Clin Nutr 18:307-311

Donnarumma F, Wintersteiger R, Schober M et al (2013) Simultaneous quantitation of alpha-ketoglutaric acid and 5-hydroxymethylfurfural in plasma by HPLC with UV and fluorescence detection. Anal Sci 29:1177-1182

Dumas F, De Bandt JP, Colomb V et al (1988) Enteral ornithine $\alpha$ ketoglutarate enhances intestinal adaptation to massive resection in rats. Metabolism 47:1366-1371

Engel JM, Mühling J, Weiss S et al (2003) Low plasma glutamine after multiple trauma: relationship with intracellular glutamine in polymorphonuclear neutrophils during prolonged ICU stay. Acta Anaesthesiol Scand 47:707-713

Epstein AC, Gleadle JM, McNeill LA et al (2001) C. elegans EGL-9 and mammalian homologs define a family of dioxygenases that regulate HIF by prolyl hydroxylation. Cell 107:43-54

Filip R (2007) Alpha-ketoglutaric acid and bone tissue metabolism. Clin Exp Med Lett 48:3-9

Filip R, Pierzynowski SG (2008) The absorption, tissue distribution and excretion of enteraly administered alpha-ketoglutarate in rats. J Anim Physiol Anim Nutr 92:182-189

Filip R, Pierzynowski SG, Lindegard B et al (2007) Alpha-ketoglutarate decreases serum levels of C-terminal cross-linking telopeptide of type I collagen (CTX) in postmenopausal women with osteopenia: six-month study. Int J Vitam Nutr Res 77:89-97

Furukawa S, Saito H, Fukatsu K et al (1997) Glutamine-enhanced bacterial killing by neutrophils from postoperative patients. Nutrition 13:863-869

Furukawa S, Saito H, Inoue T et al (2000) Supplemental glutamine augments phagocytosis and reactive oxygen intermediate production by neutrophils and monocytes from postoperative patients in vitro. Nutrition 16:323-329

Giustina A, Mazziotti G, Canalis E (2008) Growth hormone, insulinlike growth factors, and the skeleton. Endocr Rev 29:535-559

Hammarqvist F, Wernerman J, Ali R et al (1989) Addition of glutamine to total parenteral nutrition after elective abdominal surgery spares free glutamine in muscle, counteracts the fall in muscle protein synthesis, and improves nitrogen balance. Ann Surg 209:455-461

Hammarqvist F, Wernerman J, Ali R et al (1990) Effects of an amino acid solution enriched with either branched chain amino acids or ornithine a-ketoglutarate on the postoperative intracellular amino acid concentration of skeletal muscle. Br J Surg 77:214-218

Hammarqvist F, Warnerman J, Von Der Decken A et al (1991) Alphaketoglutarate preserves protein synthesis and free glutamine in skeletal muscle after surgery. Surgery 109:28-36

Hao HX, Khalimonchuk O, Schraders M et al (2009) SDH5, a gene required for flavination of succinate dehydrogenase, is mutated in paraganglioma. Science 325:1139-1142

Hariharakrishnan J, Satpute RM, Prasad GB et al (2009) Oxidative stress mediated cytotoxicity of cyanide in LLC-MK2 cells and its attenuation by alpha-ketoglutarate and $\mathrm{N}$-acetyl cysteine. Toxicol Lett 185:132-141

Harrison AP, Pierzynowski SG (2008) Biological effects of 2-oxoglutarate with particular emphasis on the regulation of protein, mineral and lipid absorption/metabolism, muscle performance, kidney function, bone formation and cancerogenesis, all viewed from a healthy ageing perspective state of the art-review article. J Physiol Pharmacol 59(suppl 1):91-106

Harrison AP, Tygesen MP, Sawa-Wojtanowicz B et al (2004) $\alpha$ ketoglutarate treatment early in postnatal life improves bone density in lambs at slaughter. Bone 35:204-209
Hausinger RP (2004) FeII/alpha-ketoglutarate-dependent hydroxylases and related enzymes. Crit Rev Biochem Mol Biol 39:21-68

He W, Miao FJ, Lin DC et al (2004) Citric acid cycle intermediates as ligands for orphan G-protein-coupled receptors. Nature 429:188-193

Hermanussen M, Tresguerres JA (2005) How much glutamate is toxic in paediatric parenteral nutrition? Acta Paediatr 94:16-19

Hirsilä M, Koivunen P, Günzler V et al (2003) Characterization of the human prolyl 4-hydroxylases that modify the hypoxia-inducible factor. J Biol Chem 278:30772-30780

Hoffmann I, Roatsch M, Schmitt ML et al (2012) The role of histone demethylases in cancer therapy. Mol Oncol 6:683-703

Hou Y, Wang L, Ding B et al (2011) Alpha-ketoglutarate and intestinal function. Front Biosci 16:1186-1196

Hou P, Kuo CY, Cheng CT et al (2014) Intermediary metabolite precursor dimethyl-2-ketoglutarate stabilizes hypoxia-inducible factor- $1 \alpha$ by inhibiting prolyl-4-hydroxylase PHD2. PLoS One 9:e113865

Hutton JJ Jr, Trappel AL, Udenfriend S (1966) Requirements for alpha-ketoglutarate, ferrous ion and ascorbate by collagen proline hydroxylase. Biochem Biophys Res Commun 24:179-184

Isaacs JS, Jung YJ, Mole DR et al (2005) HIF overexpression correlates with biallelic loss of fumarate hydratase in renal cancer: novel role of fumarate in regulation of HIF stability. Cancer Cell 8:143-153

Italiano A, Chen CL, Sung YS et al (2012) SDHA loss of function mutations in a subset of young adult wild-type gastrointestinal stromal tumors. BMC Cancer 12:408

Ito S, D'Alessio AC, Taranova OV et al (2010) Role of Tet proteins in $5 \mathrm{mC}$ to $5 \mathrm{hmC}$ conversion, ES-cell self-renewal and inner cell mass specification. Nature 466:1129-1133

Ivan M, Kondo K, Yang H et al (2001) HIF alpha targeted for VHLmediated destruction by proline hydroxylation: implications for O2 sensing. Science 292:464-468

Jaakkola P, Mole DR, Tian YM et al (2001) Targeting of HIF-alpha to the von Hippel-Lindau ubiquitylation complex by O2-regulated prolyl hydroxylation. Science 292:468-472

Jackson SH, Dennis AW, Greenberg M (1975) Iminodipeptiduria: a genetic defect in recycling collagen; a method for determining prolidase in erythrocytes. Can Med Assoc J 113(759):762-763

Janeway KA, Kim SY, Lodish M et al (2011) Defects in succinate dehydrogenase in gastrointestinal stromal tumors lacking KIT and PDGFRA mutations. Proc Natl Acad Sci USA 108:314-318

Jeevanandam M, Petersen SR (1999) Substrate fuel kinetics in enterally fed trauma patients supplemented with ornithine alpha ketoglutarate. Clin Nutr 18:209-217

Jeevanandam M, Holaday NJ, Petersen SR (1996) Ornithine alphaketoglutarate $(\mathrm{OKG})$ supplementation is more effective than its components in traumatized rats. J Nutr 126:2141-2150

Jeong SM, Haigis MC (2015) Sirtuins in cancer: a balancing act between genome stability and metabolism. Mol Cells 38:750-758

Junghans P, Derno M, Pierzynowski S et al (2006) Intraduodenal infusion of $\alpha$-ketoglutarate decreases whole body energy expenditure in growing pigs. Clin Nutr 25:489-496

Kaelin WG Jr (2005) The von Hippel-Lindau protein, HIF hydroxylation, and oxygen sensing. Biochem Biophys Res Commun 338:627-638

Kaelin WG Jr, Ratcliffe PJ (2008) Oxygen sensing by metazoans: the central role of the HIF hydroxylase pathway. Mol Cell 30:393-402

Kaminsky YG, Kosenko EA, Kondrashova MN (1982) Metabolites of citric acid cycle, carbohydrate and phosphorus metabolism, and related reactions, redox and phosphorylating states of hepatic tissue, liver mitochondria and cytosol of the pigeon, under 
normal feeding and natural nocturnal fasting conditions. Comp Biochem Physiol B 73:957-963

Karna E, Miltyk W, Wołczyński S et al (2001) The potential mechanism for glutamine-induced collagen biosynthesis in cultured human skin fibroblasts. Comp Biochem Physiol B: Comp Biochem 130:23-32

Kew S, Wells SM, Yaqoob P et al (1999) Dietary glutamine enhances murine T-lymphocyte responsiveness. J Nutr 129:1524-1531

King A, Selak MA, Gottlieb E (2006) Succinate dehydrogenase and fumarate hydratase: linking mitochondrial dysfunction and cancer. Oncogene 25:4675-4682

Kivirikko KI, Pihlajaniemi T (1998) Collagen hydroxylases and the protein disulfide isomerase subunit of prolyl 4-hydroxylases. Adv Enzymol Relat Areas Mol Biol 72:325-329

Kjellman UW, Björk K, Ekroth R et al (1997) Addition of alphaketoglutarate to blood cardioplegia improves cardioprotection. Ann Thorac Surg 63:1625-1633

Koivunen P, Hirsilä M, Remes AM et al (2007) Inhibition of hypoxiainducible factor (HIF) hydroxylases by citric acid cycle intermediates: possible links between cell metabolism and stabilization of HIF. J Biol Chem 282:4524-4532

Koivunen P, Lee S, Duncan CG et al (2012) Transformation by the (R)-enantiomer of 2-hydroxyglutarate linked to EGLN activation. Nature 483:484-488

Krebs HA (1935) Metabolism of amino-acids: the synthesis of glutamine from glutamic acid and ammonia, and the enzymic hydrolysis of glutamine in animal tissues. Biochem $\mathrm{J}$ 29:1951-1969

Krebs HA, Johnson WA (1980) The role of citric acid in intermediate metabolism in animal tissues. FEBS Lett 117 Suppl:K1-K10 (reprint from Enzymologia 1937; 4:148-156)

Kristensen NB, Jungvid H, Fernández JA et al (2002) Absorption and metabolism of alpha-ketoglutarate in growing pigs. J Anim Physiol Anim Nutr 86:239-245

Lamandé SR, Bateman JF (1999) Procollagen folding and assembly: the role of endoplasmic reticulum enzymes and molecular chaperones. Semin Cell Dev Biol 10:455-464

Latif F, Tory K, Gnarra J (1993) Identification of the von HippelLindau disease tumor suppressor gene. Science 260:1317-1320

Le Boucher J, Obled C, Farges MC et al (1997) Ornithine alphaketoglutarate modulates tissue protein metabolism in burn-injured rats. Am J Physiol 273:E557-E563

Le Boucher J, Farges MC, Minet R et al (1999) Modulation of immune response with ornithine $\alpha$-ketoglutarate in burn injury: an arginine or glutamine dependency? Nutrition 15:773-777

Letouzé E, Martinelli C, Loriot C et al (2013) SDH mutations establish a hypermethylator phenotype in paraganglioma. Cancer Cell 23:739-752

Loenarz C, Schofield CJ (2008) Expanding chemical biology of 2-oxoglutarate oxygenases. Nat Chem Biol 4:152-156

Loï C, Nakib S, Neveux N et al (2005) Ornithine alpha-ketoglutarate metabolism in the healthy rat in the postabsorptive state. Metabolism 54:1108-1114

Long LH, Halliwell B (2011) Artefacts in cell culture: $\alpha$-ketoglutarate can scavenge hydrogen peroxide generated by ascorbate and epigallocatechin gallate in cell culture. Biochem Bioph Res Commun 406:20-24

Losman JA, Looper RE, Koivunen P et al (2013) (R)-2-hydroxyglutarate is sufficient to promote leukemogenesis and its effects are reversible. Science 339:1621-1625

MacKenzie ED, Selak MA, Tennant DA et al (2007) Cell-permeating $\alpha$-ketoglutarate derivatives alleviate pseudohypoxia in succinate dehydrogenase-deficient cells. Mol Cell Biol 27:3282-3289

Majamaa K, Sasaki T, Uitto J (1987) Inhibition of prolyl hydroxylation during collagen biosynthesis in human skin fibroblast cultures by ethyl 3,4-dihydroxybenzoate. J Invest Dermatol 89:405-409

Mardis ER, Ding L, Dooling DJ et al (2009) Recurring mutations found by sequencing an acute myeloid leukemia genome. N Engl J Med 361:1058-1066

Martin M, Ferrier B, Baverel G (1989) Transport and utilization of alpha-ketoglutarate by the rat kidney in vivo. Pflugers Arch 413:217-224

Matsumoto K, Imagawa S, Obara N et al (2006) 2-oxoglutarate downregulates expression of vascular endothelial growth factor and erythropoietin through decreasing hypoxia-inducible factor- $1 \alpha$ and inhibits angiogenesis. J Cell Physiol 209:333-340

Matsumoto K, Obara N, Ema M et al (2009) Antitumor effects of 2-oxoglutarate through inhibition of angiogenesis in a murine tumor model. Cancer Sci 100:1639-1647

Maxwell PH, Pugh CW, Ratcliffe PJ (2001) Activation of the HIF pathway in cancer. Curr Opin Genet Dev 11:293-299

Maynard MA, Evans AJ, Hosomi T et al (2005) Human HIF-3alpha4 is a dominant-negative regulator of HIF-1 and is down-regulated in renal cell carcinoma. FASEB J 19:1396-1406

McDonough MA, Loenarz C, Chowdhury R et al (2010) Structural studies on human 2-oxoglutarate dependent oxygenases. Curr Opin Struct Biol 20:659-672

Meeran SM, Katiyar SK (2008) Cell cycle control as a basis for cancer chemoprevention through dietary agents. Front Biosci 13:2191-2202

Meng H, Cao Y, Qin J et al (2015) DNA methylation, its mediators and genome integrity. Int J Biol Sci 11:604-617

Mizuno N, Itoh H (2009) Functions and regulatory mechanisms of Gq-signaling pathways. Neurosignals 17:42-54

Moinard C, Chauveau B, Walrand S et al (1999) Phagocyte functions in stressed rats: comparison of modulation by glutamine, arginine and ornithine 2-oxoglutarate. Clin Sci 97:59-65

Moinard C, Caldefie F, Walrand S et al (2000) Involvement of glutamine, arginine, and polyamines in the action of ornithine alpha-ketoglutarate on macrophage functions in stressed rats. J Leukoc Biol 67:834-840

Moinard C, Caldefie F, Walrand S et al (2002) Effects of ornithine 2-oxoglutarate on neutrophils in stressed rats: evidence for the involvement of nitric oxide and polyamines. Clin Sci 102:287-295

Moinard C, Dauge V, Cynober L (2004) Ornithine $\alpha$-ketoglutarate supplementation influences motor activity in healthy rats. Clin Nutr 23:485-490

Monné M, Miniero DV, Iacobazzi V et al (2013) The mitochondrial oxoglutarate carrier: from identification to mechanism. J Bioenerg Biomembr 45:1-13

Moore SJ, Norris JC, Ho IK et al (1986) The efficacy of alphaketoglutaric acid in the antagonism of cyanide intoxication. Toxicol Appl Pharmacol 82:40-44

Moukarzel AA, Goulet O, Salas JS et al (1994) Growth retardation in children receiving long-term parenteral nutrition: effects of ornithine and $\alpha$-ketoglutarate. Am J Clin Nutr 60:408-413

Mühling J, Tussing F, Nickolaus KA et al (2010) Effects ofalphaketoglutarate on neutrophil intracellular aminoand alpha-keto acid profiles and ROS production. Amino Acids 38:167-177

Muller U, Krieglstein J (1995) Inhibitors of lipid peroxidation protect cultured neurons against cyanide-induced injury. Brain Res 678:265-268

Myara I, Myara A, Mangeot M et al (1984) Plasma prolidase activity: a possible index of collagen catabolism in chronic liver disease. Clin Chem 30:211-215

Myllyharju J (2003) Prolyl 4-hydroxylases, the key enzymes of collagen biosynthesis. Matrix Biol 22:15-24 
Newsholme P, Procopio J, Ramos Lima MM et al (2003) Glutamine and glutamate-their central role in cell metabolism and function. Cell Biochem Funct 21:1-9

Niemann S, Muller U (2000) Mutations in SDHC cause autosomal dominant paraganglioma, type 3. Nat Genet 26:268-270

Niemiec T, Sikorska J, Harrison A et al (2011) Alpha-ketoglutarate stabilizes redox homeostasis and improves arterial elasticity in aged mice. J Physiol Pharmacol 62:37-43

Norris JC, Utley WA, Hume AS (1990) Mechanism of antagonizing cyanide induced lethality by alpha-kotoglutarate. Toxicology 62:275-283

Ogle CK, Ogle JD, Mao JX et al (1994) Effect of glutamine on phagocytosis and bacterial killing by normal and pediatric burn patient neutrophils. JPEN J Parenter Enteral Nutr 18:128-133

Ohh M (2006) Ubiquitin pathway in VHL cancer syndrome. Neoplasia 8:623-629

Otto C, Yovkova V, Barth G (2011) Overproduction and secretion of $\alpha$-ketoglutarate acid by microorganisms. Appl Microbiol Biotechnol 92:689-695

Owen OE, Kalhan SC, Hanson RW (2002) The key role of anaplerosis and cataplerosis for citric acid cycle function. J Biol Chem 277:30409-30412

Palmieri F, Quagliariello E, Klingenberger M (1972) Kinetics and specificity of the oxoglutarate carrier in rat-liver mitochondria. Eur J Biochem 29:408-416

Parsons DW, Jones S, Zhang X et al (2008) An integrated genomic analysis of human glioblastoma multiforme. Science 321:1807-1812

Petersen L, Olewinski R, Salmon P et al (2003) Novel proline hydroxylase activities in the pneumocandin-producing fungus Glarealozoyensis responsible for the formation of trans 3- and trans 4-hydroxyproline. Appl Microbiol Biotechnol 62:263-267

Pollard PJ, Briere JJ, Alam NA et al (2005) Accumulation of Krebs cycle intermediates and over-expression of HIF1alpha in tumours which result from germline $\mathrm{FH}$ and SDH mutations. Hum Mol Genet 14:2231-2239

Pugh CW, Ratcliffe PJ (2003) The von Hippel-Lindau tumor suppressor, hypoxia-inducible factor-1 (HIF-1) degradation, and cancer pathogenesis. Semin Cancer Biol 13:83-89

Radzki RP, Bienko M, Pierzynowski SG (2012) Anti-osteopenic effect of alpha-ketoglutarate sodium salt in oviarectomized rats. J Bone Miner Metab 30:651-659

Raimundo N, Baysal BE, Shadel GS (2011) Revisiting the TCA cycle: signaling to tumor formation. Trends Mol Med 17:641-649

Raul F, Gosse F, Galluser M et al (1995) Functional and metabolic changes in intestinal mucosa of rats after enteral administration of ornithine alpha-ketoglutarate salt. JPEN JPEN J Parenter Enteral Nutr 19:145-150

Ricketts C, Woodward ER, Killick P et al (2008) Germline SDHB mutations and familial renal cell carcinoma. J Natl Cancer Inst 100:1260-1262

Riedel E, Nündel M, Hampl H (1996) alpha-Ketoglutarate application in hemodialysis patients improves amino acid metabolism. Nephron 74:261-265

Robinson LE, Bussière F, Le Boucher J et al (1999) Amino acid nutrition and immune function in tumour-bearing rats: a comparison of glutamine-, arginine- and ornithine 2-oxoglutarate-supplemented diets. Clin Sci 97:657-669

Rocchiccioli F, Leroux JP, Cartier PH (1984) Microdetermination of 2-ketoglutaric acid in plasma and cerebrospinal fluid by capillary gas chromatography mass spectrometry; application to pediatrics. Biomed Mass Spectrom 11:24-28

Roch-Arveiller M, Tissot M, Coudray-Lucas C et al (1996) Immunomodulatory effects of ornithine alpha-ketoglutarate in rats with burn injuries. Arch Surg 131:718-723
Roch-Arveiller M, Fontagné J, Coudray-Lucas C et al (1999) Ornithine $\alpha$-ketoglutarate counteracts the decrease of liver cytochrome P-450 content in burned rats. Nutrition 15:379-383

Rodríguez-Paredes M, Esteller M (2011) Cancer epigenetics reaches mainstream oncology. Nat Med 17:330-339

Rose NR, McDonough MA, King ON et al (2011) Inhibition of 2-oxoglutarate dependent oxygenases. Chem Soc Rev 40:4364-4397

Rosen HN, Chen V, Cittadini A et al (1995) Treatment with growth hormone and IGF-1 in growing rats increases bone mineral content but not bone mineral density. J Bone Miner Res 10:1352-1358

Rzeski W, Walczak K, Juszczak M et al (2012) Alpha-ketoglutarate $(\mathrm{AKG})$ inhibits proliferation of colon adenocarcinoma cells in normoxic conditions. Scnad J Gastroenterol 47:565-571

Sacewicz I, Wiktorska M, Wysocki T et al (2009) Mechanisms of cancer angiogenesis (Article in Polish). Postepy Hig Med Dosw 63:159-168

Saito H, Furukawa S, Matsuda T (1999) Glutamine as an immunoenhancing nutrient. JPEN J Parenter Enteral Nutr 23(5 Suppl):S59-S61

Salminen A, Kaarniranta K, Hiltunen M et al (2014) Krebs cycle dysfunction shapes epigenetic landscape of chromatin: novel insights into mitochondrial regulation of aging process. Cell Signal 26:1598-1603

Schaap FG, French PJ, Bovée JV (2013) Mutations in the isocitrate dehydrogenase genes IDH1 and IDH2 in tumors. Adv Anat Pathol 20:32-38

Schofield CJ, Ratcliffe PJ (2005) Signalling hypoxia by HIF hydroxylases. Biochem Biophys Res Commun 338:617-626

Schofield CJ, Zhang Z (1999) Structural and mechanistic studies on 2-oxoglutarate-dependent oxygenases and related enzymes. Curr Opin Struct Biol 9:722-731

Ségaud F, Lardeux B, Alexandre-Gouabau MC et al (2005) Pretreatment of starved rats with ornithine $\alpha$-ketoglutarate: effects on hepatic mRNA levels and plasma concentrations of three liversecreted proteins. Nutrition 21:732-739

Selak MA, Armour SM, MacKenzie ED et al (2005) Succinate links TCA cycle dysfunction to oncogenesis by inhibiting HIF-alpha prolyl hydroxylase. Cancer Cell 7:77-85

Semenza GL (2013) HIF-1 mediates metabolic responses to intratumoral hypoxia and oncogenic mutations. J Clin Invest 123:3664-3671

Sena LA, Chandel NS (2012) Physiological roles of mitochondrial reactive oxygen species. Mol Cell 48:158-167

Smith RJ, Downing SJ, Phang JM et al (1980) Pyrroline-5-carboxylate synthase activity in mammalian cells. Proc Natl Acad Sci USA 77:5221-5225

Sokołowska M, Oleszek A, Włodek L (1999) Protective effect of alpha-keto acids on the oxidative hemolysis. Pol J Pharmacol 51:429-434

Solomonson LP (1981) Cyanide as a metabolic inhibitor. In: Vennesland B, Conn EE, Knowles CJ, Westley J, Vissing F (eds) Cyanide in biology. Academic Press, New York, p 11

Son ED, Choi GH, Kim H et al (2007) Alpha-ketoglutarate stimulates procollagen production in cultured human dermal fibroblasts, and decreases UVB-induced Wrinkle formation following topical application on the dorsal skin of hairless mice. Biol Pharm Bull 30:1395-1399

Sookoian S, Pirola CJ (2015) Liver enzymes, metabolomics and genome-wide association studies: from systems biology to the personalized medicine. World J Gastroenterol 21:711-725

Stehle P, Zander J, Mertes N et al (1989) Effect of parenteral glutamine peptide supplements on muscle glutamine loss and nitrogen balance after major surgery. Lancet 1:231-233 
Stein J, Boehles HJ, Blumenstein I, Goeters C, Schulz R (2009) Amino acids-guidelines on parenteral nutrition, Chapter 4. Ger Med Sci 7:Doc24

Stoll B, McNelly S, Buscher HP et al (1991) Functional hepatocyte heterogeneity in glutamate, aspartate and alpha-ketoglutarate uptake: a histoautoradiographical study. Hepatology 13:247-253

Stratakis CA, Carney JA (2009) The triad of paragangliomas, gastric stromal tumours and pulmonary chondromas (Carney triad), and the dyad of paragangliomas and gastric stromal sarcomas (Carney-Stratakis syndrome): molecular genetics and clinical implications. J Intern Med 266:43-52

Tahiliani M, Koh KP, Shen Y et al (2009) Conversion of 5-methylcytosine to 5-hydroxymethylcytosine in mammalian DNA by MLL partner TET1. Science 324:930-935

Tarhonskaya H, Rydzik AM, Leung IK et al (2014) Non-enzymatic chemistry enables 2-hydroxyglutarate-mediated activation of 2-oxoglutarate oxygenases. Nat Commun 5:3423

Tatara MR, Brodzki A, Krupski W et al (2005) Effects of $\alpha$ ketoglutarate on bone homeostasis and plasma amino acids in turkeys. Poult Sci 84:1604-1609

Tatara MR, Śliwa E, Krupski W et al (2006) Ornithine alphaketoglutarate increases mineralization and mechanical properties of tibia in turkeys. Bone 39:100-105

Tatara MR, Tygesen MP, Sawa-Wojtanowicz B et al (2007) Bone development: the effect of short-term alpha-ketoglutarate administration on long-term mechanical properties of ribs in ram lambs. Small Ruminant Res 67:179-183

Tatara MR, Krupski W, Tymczyna B et al (2012) Effects of combined maternal administration with alpha-ketoglutarate (AKG) and beta-hydroxy-methylbutyrate (HMB) on prenatal programming of skeletal properties in the offspring. Nutr Metab 9:39

Tennant D, Frezza C, MacKenzie ED et al (2009) Reactivating HIF prolyl hydroxylases under hypoxia results in metabolic catastrophe and cell death. Oncogene 28:4009-4021

Tokonami N, Morla L, Centeno G et al (2013) $\alpha$-Ketoglutarate regulates acid-base balance through an intrarenal paracrine mechanism. J Clin Invest 123:3166-3171

Tomlinson IP, Alam NA, Rowan AJ (2002) Germline mutations in FH predispose to dominantly inherited uterine fibroids, skin leiomyomata and papillary renal cell cancer. Nat Genet 30:406-410

Tsukada Y, Fang J, Erdjument-Bromage H et al (2006) Histone demethylation by a family of JmjC domain-containing proteins. Nature 439:811-816

Tulsawani RK, Debnath M, Pant SC et al (2005) Effect of sub-acute oral cyanide administration in rats: protective efficacy of alphaketoglutarate and sodium thiosulfate. Chem-Biol Interact 156:1-12

Vanharanta S, Buchta M, McWhinney SR et al (2004) Early-onset renal cell carcinoma as a novel extraparaganglial component of SDHB-associated heritable paraganglioma. Am J Hum Genet 74:153-159

Varma SD, Hegde KR (2004) Effect of alpha-ketoglutarate against selenite cataract formation. Exp Eye Res 79:913-918

Vaubourdolle M, Jardel A, Coudray-Lucas C et al (1988) Metabolism and kinetics of parenterally administered ornithine and $\alpha$ ketoglutarate in healthy and burned animals. Clin Nutr 7:105-111

Vaubourdolle M, Coudray-Lucas C, Jardel A et al (1991) Action of enterally administered ornithine alpha-ketoglutarate on protein breakdown in skeletal muscle and liver of the burned rat. JPEN J Parenter Enteral Nutr 15:517-520

Velvizhi S, Dakshayani KB, Subramanian P (2002a) Effects of alphaketoglutarate on antioxidants and lipid peroxidation products in rats treated with ammonium acetate. Nutrition 18:747-750

Velvizhi S, Nagalashmi T, Essa MM et al (2002b) Effects of alphaketoglutarate on lipid peroxidation and antioxidant status during chronic ethanol administration in Wistar rats. Pol J Pharmacol 54:231-236

Vinnars E, Bergstöm J, Fürst P (1975) Influence of the postoperative state on the intracellular free amino acids in human muscle tissue. Ann Surg 182:665-671

Wagner BM, Donnarumma F, Wintersteiger R et al (2010) Simultaneous quantitative determination of alpha-ketoglutaric acid and 5-hydroxymethylfurfural in human plasma by gas chromatography-mass spectrometry. Anal Bioanal Chem 396:2629-2637

Welborn JR, Shpun S, Dantzler WH et al (1998) Effect of alphaketoglutarate on organic anion transport in single rabbit renal proximal tubules. Am J Physiol 274(1 Pt 2):F165-F174

Wells SM, Kew S, Yaqoob P et al (1999) Dietary glutamine enhances cytokine production by murine macrophages. Nutrition $15: 881-884$

Wernerman J, Hammarqvist F, Von Der Decken A et al (1987) Ornithine-alpha-ketoglutarate improves skeletal muscle protein synthesis as assessed by ribosome analysis and nitrogen use after surgery. Ann Surg 206:674-678

Wiesener MS, Jürgensen JS, Rosenberger C et al (2003) Widespread hypoxia-inducible expression of HIF-2alpha in distinct cell populations of different organs. FASEB J 17:271-293

Wittenberger T, Hellebrand S, Munck A et al (2002) GPR99, a new G protein-coupled receptor with homology to a new subgroup of nucleotide receptors. BMC Genom 3:17

Xiao M, Yang H, Xu W et al (2012) Inhibition of $\alpha$-KG-dependent histone and DNA demethylases by fumarate and succinate that are accumulated in mutations of $\mathrm{FH}$ and $\mathrm{SDH}$ tumor suppressors. Genes Dev 26:1326-1338

Xiong Y, Hannon GJ, Zhang $\mathrm{H}$ et al (1993) p21 is a universal inhibitor of cyclin kinases. Nature 366:701-704

Xu W, Yang H, Liu Y et al (2011) Oncometabolite 2-hydroxyglutarate is a competitive inhibitor of $\alpha$-ketoglutarate-dependent dioxygenases. Cancer Cell 19:17-30

Yamamoto H, Mohanan PV (2003) Effect of $\alpha$-ketoglutarate and oxaloacetate on brain mitochondrial DNA damage and seizures induced by kainic acid in mice. Toxicol Lett 143:115-122

Yao K, Yin Y, Li X et al (2012) Alpha-ketoglutarate inhibits glutamine degradation and enhances protein synthesis in intestinal porcine epithelial cells. Amino Acids 42:2491-2525

Yu F, White SB, Zhao Q et al (2001) HIF-1alpha binding to VHL is regulated by stimulus-sensitive proline hydroxylation. Proc Natl Acad Sci USA 98:9630-9635

Yudkoff M, Nelson D, Daikhin Y et al (1994) Tricarboxylic acid cycle in rat brain synaptosomes. Fluxes and interactions with aspartate aminotransferase and malate/aspartate shuttle. J Biol Chem 269:27414-27420

Zhao S, Lin Y, Xu W et al (2009) Glioma-derived mutations in IDH1 dominantly inhibit IDH1 catalytic activity and induce HIF1alpha. Science 324:261-265

Ziegler TR, Daignault NM (2000) Glutamine regulation of human immune cell function. Nutrition 16:458-459 